\title{
An Integrated Method for Determining the Oceanic Bottom Mixed Layer Thickness Based on WOCE Potential Temperature Profiles
}

\author{
PENG-Qi HuANG \\ State Key Laboratory of Tropical Oceanography, South China Sea Institute of Oceanology, Chinese Academy of Sciences, \\ Guangzhou, and University of Chinese Academy of Sciences, Beijing, China \\ Xian-Rong Cen, Yuan-Zheng Lu, Shuang-Xi Guo, And Sheng-Qi Zhou \\ State Key Laboratory of Tropical Oceanography, South China Sea Institute of Oceanology, \\ Chinese Academy of Sciences, Guangzhou, China
}

(Manuscript received 13 February 2018, in final form 24 August 2018)

\begin{abstract}
In this study we examined the applicability of the threshold, curvature, maximum angle, and relative variance methods for identifying the oceanic bottom mixed layer (BML) thickness $H_{\mathrm{BML}}$. Using full-depth temperature profiles along 17 WOCE sections covering the Atlantic, Indian, and Pacific Oceans, we found that the BML thicknesses determined based on the threshold, curvature, and maximum angle methods had wider $95 \%$ confidence intervals and much lower quality indexes $(\mathrm{QI}<0.57)$ compared with those based on the visual inspection $(\mathrm{QI}=0.68)$. The relative variance method appeared to perform better than the other methods because the $95 \%$ confidence interval and QI (0.60) values were closer to those determined based on the visual inspection, although differences were still present. We then proposed an integrated method by optimizing the possible $H_{\mathrm{BML}}$ values obtained from the four methods. The BML thicknesses determined using the integrated method were closest to those based on the visual inspection according to the higher QI (0.64) and more stations $(71 \%)$ with QI $>0.5$. Compared with the results in previous studies, the integrated method determined the consistent BML thicknesses in most regions (e.g., the northern Atlantic), and it also effectively identified the BML thicknesses in some regions where the BML was considered to be not readily detectable (e.g., the Madeira Abyssal Plain).
\end{abstract}

\section{Introduction}

In oceans, the bottom mixed layer (BML) is the region adjacent to the ocean floor, where active mixing promoted by bottom shear and internal wave breaking leads to a vertically quasi-homogeneous profile in terms of the temperature, salinity, density, and other properties. Many interrelated physical, geochemical, and biological processes actively take place inside the BML, and these processes communicate with the ocean interior and underlying sediments (Bowden 1978; Grant and Madsen 1986; Richards 1990). The BML was first observed in the 1970s (Amos et al. 1971; Weatherly 1972; Armi and Millard 1976; Caldwell 1976). Various mechanisms, such as ocean mixing (Ferrari et al. 2016; McDougall and Ferrari 2017), geothermal heating (Adcroft et al. 2001; Zhou and Lu 2013), and diffusion-driven flow (Wunsch

\footnotetext{
Corresponding author: Sheng-Qi Zhou, sqzhou@scsio.ac.cn
}

1970), may be responsible for the formation of the BML. The variance and dynamics of the BML were studied extensively in regional oceans (e.g., Armi and Millard 1976; Grant and Madsen 1986; Lentz and Trowbridge 1991; Perlin et al. 2005), and lakes (e.g., Gloor et al. 1994; Wüest and Lorke 2003). The BML can be characterized by several parameters, where the most important and fundamental is the thickness of the BML $\left(H_{\mathrm{BML}}\right)$. The BML is typically a few tens to hundreds of meters thick in the oceans (e.g., Armi and Millard 1976; Weatherly and Martin 1978; Hogg et al. 1982) but much less in lakes, with a thickness of only a few meters or less (see Wüest and Lorke 2003). Many studies have aimed to formulate $H_{\mathrm{BML}}$ so that the BML can be described well (Pollard et al. 1972; Armi and Millard 1976; Weatherly and Martin 1978; Richards 1982; Zilitinkevich and Esau 2002; Perlin et al. 2007), where both the ocean boundary layer and the atmosphere boundary layer have been considered. It is unclear whether the BML can be 
treated as the classical Ekman layer (Armi and Millard 1976) or whether more parameters need to be considered (Weatherly and Martin 1978; Richards 1982; Zilitinkevich and Esau 2002; Perlin et al. 2007). However, the accurate determination of $H_{\mathrm{BML}}$ is a priority when exploring the optimal parameterization of BML and the physical, biological, and geochemical processes within the BML.

In earlier studies a threshold method, based on temperature or density profiles, was the main approach employed to determine the thickness of the BML. However, the threshold values differ widely among various ocean regions. On the Oregon shelf, the temperature threshold was determined as $0.002^{\circ} \mathrm{C}$ by Caldwell (1976) and a density difference of $0.0006 \mathrm{~kg} \mathrm{~m}^{-3}$, which is equivalent to a temperature difference of $0.01^{\circ} \mathrm{C}$, was used as a criterion by Perlin et al. (2005). On the California shelf, the temperature threshold was $0.02^{\circ} \mathrm{C}$ for conductivity-temperature-depth (CTD) observations and $0.05^{\circ} \mathrm{C}$ for the moored measurements (Lentz and Trowbridge 1991). The temperature threshold was determined as $0.2^{\circ}$ or $0.4^{\circ} \mathrm{C}$ on the southeastern Australian shelf (in water depths between 65 and $140 \mathrm{~m}$ ) (Schaeffer et al. 2014). In the Madeira Abyssal Plain and the Vema Channel, a temperature departure of $0.001^{\circ} \mathrm{C}$ from the bottom temperature was employed to identify $H_{\mathrm{BML}}$ (Bowden 1978; Hogg et al. 1982). In some transoceanic sections in the Northern Atlantic, the temperature threshold was taken as $0.005^{\circ} \mathrm{C}$ (Lozovatsky et al. 2008; Lozovatsky and Shapovalov 2012). A temperature difference of $0.005^{\circ} \mathrm{C}$ was also used at an abyssal station off central California (Beaulieu and Baldwin 1998). In a study in the northwestern Mediterranean, a density difference of $0.0005 \mathrm{~kg} \mathrm{~m}^{-3}$ was used to identify $H_{\mathrm{BML}}$ (Durrieu de Madron et al. 2017). Banyte et al. (2018) recently mapped the weakly stratified bottom boundary layer of the global ocean with a density criteria of $1 \times 10^{-5} \mathrm{~kg} \mathrm{~m}^{-4}$. In addition, buoyancy frequency $N$ has been used occasionally. For example, $N^{2}$ falling below $2 \times 10^{-7} \mathrm{~s}^{-2}$ was taken as the threshold value at the Blake Outer Ridge to survey the North Atlantic Deep Western Boundary Current (Stahr and Sanford 1999). In Lake Erie, the water density threshold was set as $0.001 \mathrm{~kg} \mathrm{~m}^{-3}$ (Valipour et al. 2015). According to Lentz and Trowbridge (1991), the determination of $H_{\mathrm{BML}}$ is highly sensitive to the temperature threshold, especially in a weakly stratified background.

Furthermore, many studies have attempted to developing methods for accurately calculating the oceanic surface mixed layer depth (Defant 1936; Wyrtki 1964; Levitus 1982; Lukas and Lindstrom 1991; Brainerd and Gregg 1995; Obata et al. 1996; Kara et al. 2000; Lavender et al. 2002; Thomson and Fine 2003; Lorbacher et al. 2006; Holte and Talley 2009; Chu and Fan 2011; Huang et al. 2018).
In particular, the threshold method is the most popular one because it is simple and can presumably be applied to profiles with various vertical resolutions (see Kara et al. 2000; Thomson and Fine 2003; de Boyer Montégut et al. 2004; Lorbacher et al. 2006; Holte and Talley 2009. Many other relatively sophisticated approaches have been proposed, such as a curvature-based method (Lorbacher et al. 2006); a linear optimal fitting method, developed further as a maximum angle method (Chu and Fan 2010, 2011); and a relative variance method (Huang et al. 2018). These methods are less dependent on arbitrary criteria so that the surface mixed layer depth can be determined objectively.

In this study we examined the applicability of the threshold, curvature, maximum angle, and relative variance methods for determining $H_{\mathrm{BML}}$ using data along 17 World Ocean Circulation Experiment (WOCE) sections in different oceans. We also proposed an integrated method by optimizing all of these possible BML thicknesses obtained with these methods. The remainder of this paper is organized as follows. In section 2 we describe the hydrographic data and methodology. In section 3 we illustrate the performances of different methods for identifying $H_{\mathrm{BML}}$ by using potential temperature profiles along 17 WOCE sections in the Pacific, Indian, and Atlantic Oceans, and explain the proposed integrated method for detecting the BML thickness $H_{\mathrm{BML}}$ with higher credibility. In section 4 we compare the values of $H_{\mathrm{BML}}$ determined by the new method with those in previous studies. We summarize our results in section 5 .

\section{Data and methods}

\section{a. Hydrographical data}

We used temperature and salinity data obtained from the CTD profilers in the WOCE, the U.S. Climate Variability and Predictability (CLIVAR) Program, and other programs, which were downloaded from the CLIVAR and Carbon Hydrographic Data Office website (https://cchdo.ucsd.edu/) on 9 July 2015. For most of the WOCE stations, the ocean depths (corrected or uncorrected depths) and the minimum distance from the bottom (DAB) could be downloaded from the same website. In this database, the temperature and salinity data were generally measured over the full ocean depth to the very bottom, thereby providing a robust view of the deep water column and the BML in regions with varying conditions. Seventeen WOCE sections [see Table 1 for the section names and expedition codes (EXPOCODEs) information], including 1680 stations, were selected to cover the Pacific, Indian, and Atlantic 
TABLE 1. List of the 17 WOCE sections used in this study and their EXPOCODEs.

\begin{tabular}{rlll}
\hline \hline No. & Basin & WOCE section & EXPOCODE \\
\hline 1 & Atlantic & A03 & 90CT40_1 \\
2 & & A09 & 06MT15_3 \\
3 & & A16S & 33RO200501 \\
4 & & AR21 & 3175MB93 \\
5 & Indian & I03 & 316N145_8 \\
6 & & ISS01 & 74DI207 \\
7 & & IR04 & 3175MB95_07 \\
8 & Pacific & P02T & 49K6KY9401_1 \\
9 & & P04E & 32MW893_3 \\
10 & & P04W & 32MW893_1 \\
11 & & P06E & 49NZ200309_2 \\
12 & & P14N & 325023_1 \\
13 & & P15N & 18DD9403_2 \\
14 & & P15S & 3175CG90_1 \\
15 & & P16S & 33RR200501 \\
16 & & PR06 & 18DD9403_1 \\
17 & & PRS2 & 33KI165_1 \\
\hline
\end{tabular}

Oceans, as shown in Fig. 1. The vertical resolution was $2 \mathrm{~m}$ for most of the profiles (14 sections) and $1 \mathrm{~m}$ for the other profiles ( 3 sections). To compare our results with previous observations, we also selected the WOCE stations nearest to the locations measured previously. At each location considered in previous studies, the three nearest stations were selected when many stations were within $100 \mathrm{~km}$, or only one of the nearest stations was selected when no station was within $100 \mathrm{~km}$. In total, 46 WOCE stations were identified, as marked in Fig. 1.

In CTD data, salinity is typically computed in terms of the temperature and conductivity data, and it is considerably much noisier because of the instrument's errors, which include the mismatch in response time of temperature and conductivity sensors, the thermal inertia of the conductivity cell, and so on (Galbraith and Kelley 1996). The potential density profiles are also rather spiky because of the effect of the salinity data. Moreover, the potential density is often affected by the selection of the reference pressures for stations at different ocean depths. Therefore, the potential temperature was used to determine the BML thickness at each station. ${ }^{1}$

\section{b. Methodology}

As mentioned in section $1, H_{\mathrm{BML}}$ is mainly determined using the threshold method, but it is difficult to select a suitable threshold. In this study we employed four

\footnotetext{
${ }^{1}$ One reviewer suggests that the integrated method would be much more compelling if it can be applied to analyze the potential density or salinity data.
}

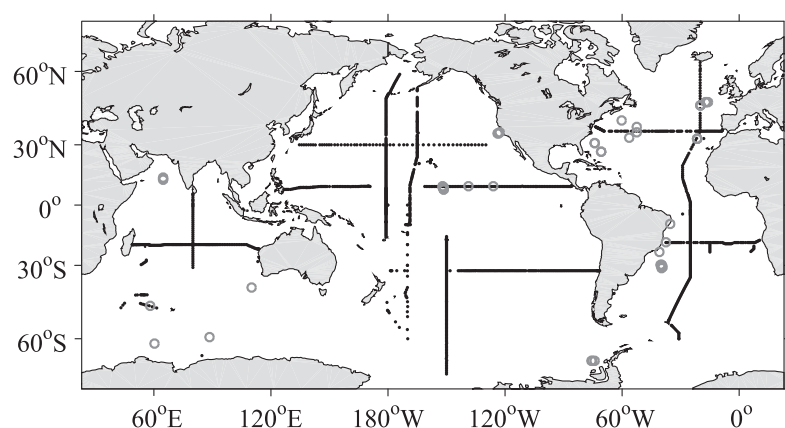

FIG. 1. Spatial distribution of WOCE data used in the study. In total, 17 WOCE sections (black) were selected to estimate the BML thickness with different methods. The 46 WOCE stations used to compare with earlier observations are marked (gray circles).

methods that have been used previously for detecting the surface ocean mixed layer depth in order to determine the BML based on the WOCE data and to examine their performances compared with the visual inspections. Rather than tracking the surface ocean mixed layer depth from the top (sea surface), we tracked the upper bound of the BML from the deepest CTD measurement, and the thickness in between is referred to as $H_{b}$. Finally, the sum of $H_{b}$ and the minimum distance from the bottom $d H$ yielded the BML thickness, that is, $H_{\mathrm{BML}}=H_{b}+d H$. These methods used for detecting $H_{b}$ are described as follows.

1) Threshold method (Thre): For abyssal ocean, we considered the threshold value employed in previous studies (Beaulieu and Baldwin 1998; Lozovatsky et al. 2008; Lozovatsky and Shapovalov 2012), where a temperature difference of $0.005^{\circ} \mathrm{C}$ was used. In addition, a linear interpolation between the observed levels was employed to determine $H_{b}$ more accurately, in a similar manner to the determination of the surface ocean mixed layer depth (de Boyer Montégut et al. 2004). As reported in previous studies, this method could give a coarse representation of the mixed layer depths, which are generally thicker than the actual ones (Lorbacher et al. 2006; Holte and Talley 2009; Huang et al. 2018).

2) Curvature method (Curv): This method was proposed by Lorbacher et al. (2006) for detecting the oceanic surface mixed layer depth. By examining the second derivative of the temperature or density profiles, which is referred to as the curvature, the first maximum from the sea surface was used to identify the mixed layer depth, as well as certain criteria of the temperature (density) gradient and standard deviation. The algorithm for this method is publicly available in Lorbacher et al. (2006). 
The fluctuations in the abyssal temperature are much weaker than those in the upper ocean, so these criteria were changed accordingly for detecting the BML. Based on a comparison with the visual inspection results, a criterion, the ratio of the temperature gradient relative to its maximum gradient, was set as larger than 0.005 ; and the other, a temperature fluctuation parameter $\delta_{30}$ (the standard deviation of temperature over the 30-m-depth interval above the current level), was set as $\delta_{30}>0.0003^{\circ} \mathrm{C}$ so that the BML could be determined fairly with this method. The curvature method deals with the second derivative, so it is effective for a highly homogeneous mixed layer. However, this method often produces problematic results with "wriggly" profiles (Lorbacher et al. 2006; Chu and Fan 2011; Huang et al. 2018).

3) Maximum angle method (Max Ang): This method is relatively independent of the selection of a threshold (Chu and Fan 2011). From the sea surface, two linear regressions were applied to the temperature or density profiles, with one above and the other beneath the depth of interest. The depth that maximized the included angle between the two linear fits was identified as the surface ocean mixed layer depth. To detect the BML, the angle between two linear regressions of $15 \mathrm{~m}$ was tracked upward from the deepest CTD, and the depth of the maximum angle was defined as the upper bound of the BML. Chu and Fan (2011) suggested that this method is unsuitable for low-resolution profiles. However, the test of vertical resolutions from 0.04 to 25 dbar by Huang et al. (2018) demonstrated that this method works well for low-resolution profiles rather than highresolution profiles.

4) Relative variance method (Rel Var): As in this method proposed by Huang et al. (2018), a relative variance is defined as the ratio of the root-mean-square relative to the absolute difference from a reference depth level. Then a relative variance profile is obtained for each temperature or density profile. The depth at the minimum value of the relative variance is used to identify the boundary of the mixed layer. Details of the algorithm were given by Huang et al. (2018). We adapted this method to detect the upper bound of the BML by tracking the minimum value of the relative variance upward from the deepest CTD. According to Huang et al. (2018), this method is robust for capturing the intersection of a homogeneous mixed layer with the underlying water of the sharp gradient in the temperature profiles at any depth resolution.

For the oceanic surface mixed layer, Lorbacher et al. (2006) proposed a quality index QI for evaluating whether a method can clearly separate the homogeneous mixed layer from the attached strongly stratified water layer,

$$
\mathrm{QI}=1-\frac{\delta_{H}}{\delta_{1.5 \times H}},
$$

where $\delta_{H}$ is the standard deviation of temperature (density) within the mixed layer and $\delta_{1.5 \times H}$ is the standard deviation of temperature (density) over the depth range from the reference level to 1.5 times the mixed layer depth. Based on the definition of QI, it is expected that QI approaches 1 when the mixed layer is well developed. A low QI value corresponds to either a mixed layer with complex structures or that a well-mixed layer cannot be identified accurately. According to Lorbacher et al. (2006), the mixed layer interpretation is impossible when $\mathrm{QI}<0.5$.

\section{Applicability of different methods}

\section{a. Examples of profiles}

First, we show the efficiency of these methods at determining $H_{b}$ using temperature profiles. As shown in Fig. 2, the minimum distance from the bottom $d H$ is added to $H_{b}$ to indicate $H_{\mathrm{BML}}$.

At the station located at $29.98^{\circ} \mathrm{N}, 167.41^{\circ} \mathrm{W}$ in the Pacific Ocean (Fig. 2a), the BML had a homogeneous temperature and it was well separated from the overlying water column of the sharp temperature gradient. The upper bound of the BML was readily determined as $94 \mathrm{~m}$ based on visual inspection. Most of the methods were effective at detecting the upper bound of the BML, which was identified as $96.4,90.6$, and $88.7 \mathrm{~m}$ by the curvature, maximum angle, and relative variance methods, respectively; and QI was around 0.90. The threshold method approximately captured the upper bound of BML, but it was limited by the fixed threshold, which resulted in a thick $H_{\mathrm{BML}}$ of $131.93 \mathrm{~m}$ and a low QI of 0.57 .

In some cases, a thick BML was identified by visual inspection, as shown in the example profile in Fig. $2 \mathrm{~b}\left(44.00^{\circ} \mathrm{N}, 178.99^{\circ} \mathrm{W}\right.$ in the Pacific Ocean), that is, $H_{\mathrm{BML}}=855 \mathrm{~m}$ and $\mathrm{QI}=0.95$. The relative variance and curvature methods yielded the closest $H_{\mathrm{BML}}$ value to the visual inspection - that is, 847.7 and $898.2 \mathrm{~m}$, respectivelywith high $\mathrm{QI} \geq 0.95$. The threshold method determined $H_{\text {BML }}$ as $998.2 \mathrm{~m}$ with a slightly lower QI (0.89). The maximum angle methods clearly overestimated $H_{\mathrm{BML}}$, which corresponded to the lowest QI in all the methods at 0.79 .

In the cases where the temperature changed gradually as the depth increased-for example, as shown in Fig. 2c $\left(24.50^{\circ} \mathrm{N}, 43.28^{\circ} \mathrm{W}\right.$ in the Atlantic Ocean $)-H_{\mathrm{BML}}$ was visually inspected as $68.6 \mathrm{~m}$, which corresponded to the 

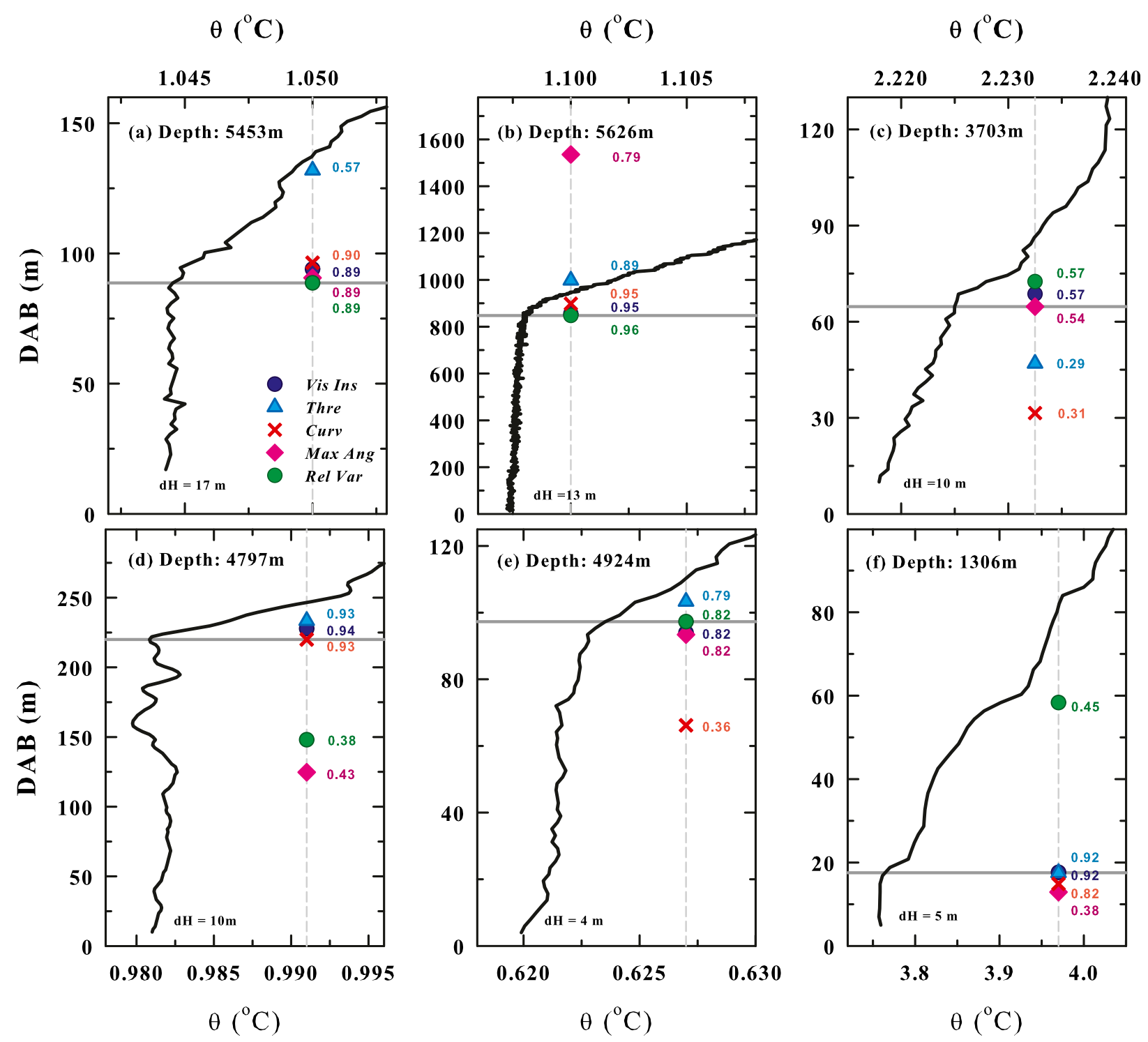

FIG. 2. Examples of potential temperature profiles at (a) $29.98^{\circ} \mathrm{N}, 167.41^{\circ} \mathrm{W}$ in the Pacific Ocean; (b) $44.00^{\circ} \mathrm{N}, 178.99^{\circ} \mathrm{W}$ in the Pacific Ocean; (c) $24.50^{\circ} \mathrm{N}, 43.28^{\circ} \mathrm{W}$ in the Atlantic Ocean; (d) $23.00^{\circ} \mathrm{S}, 15.00^{\circ} \mathrm{E}$ in the Atlantic Ocean; (e) $20.00^{\circ} \mathrm{S}, 52.78^{\circ} \mathrm{E}$ in the Indian Ocean; and (f) $22.14^{\circ} \mathrm{S}, 113.17^{\circ} \mathrm{E}$ in the Indian Ocean. The values of $H_{\mathrm{BML}}$ evaluated based on visual inspection and using different methods are marked by color symbols or lines: visual inspection (blue circle), threshold (cyan triangle), curvature (red cross), maximum angle (pink diamond), relative variance (green circle), and integrated (gray line) methods. The QI value for each method is also given using the corresponding color.

highest QI of 0.57 . The $H_{\mathrm{BML}}$ values determined by different methods were highly scattered - that is, 72.5 , 64.7, 46.9, and $31.5 \mathrm{~m}$ using the relative variance, maximum angle, threshold, and curvature methods, respectively-and QI varied from 0.57 to 0.29 . However, the $H_{\mathrm{BML}}$ values obtained by the relative variance and maximum angle methods were closest to the visually inspected one.

When the temperature fluctuated strongly within the BML, as shown in Fig. $2 \mathrm{~d}\left(23.00^{\circ} \mathrm{S}, 15.00^{\circ} \mathrm{E}\right.$ in the
Atlantic Ocean), $H_{\mathrm{BML}}$ was visually inspected as $227.8 \mathrm{~m}$ with the highest QI of 0.94 . The curvature and threshold methods approximately captured the $H_{\mathrm{BML}}$ values, which were 220.0 and $233.5 \mathrm{~m}$, respectively, with the same QI of 0.93 . The maximum angle and relative variance methods found the upper bound of the bottom depth range at a relatively homogeneous temperature with $H_{\mathrm{BML}}$ values of 124.7 and $148.0 \mathrm{~m}$, respectively; and QI values were much lower at 0.43 and 0.38 , respectively. 

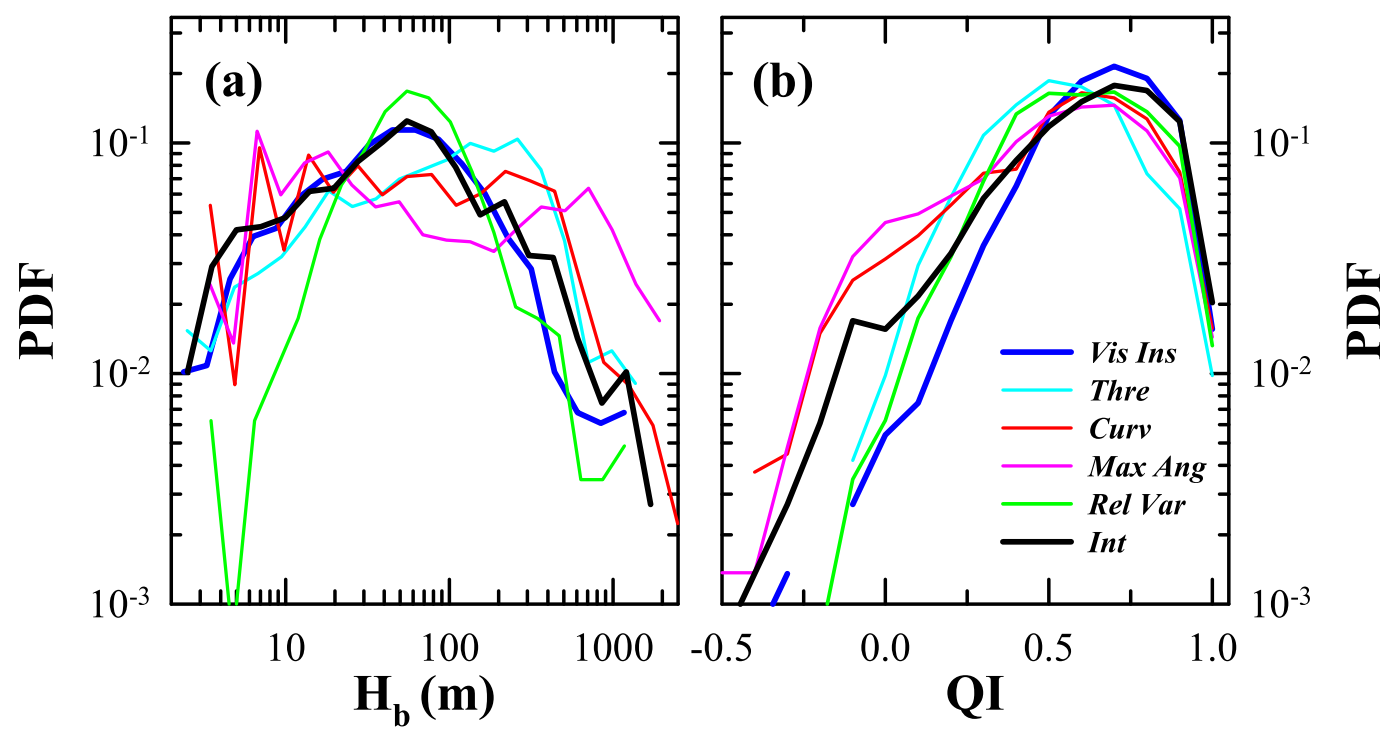

FIG. 3. PDFs for (a) $H_{b}$ and (b) QI based on the temperature profiles of 17 WOCE sections determined by visual inspection (thick blue curve) and by using the threshold (thin cyan curve), curvature (thin red curve), maximum angle (thin pin curve), relative variance (thin green curve), and integrated (thick black curve) methods.

Occasionally, the water column near the deepest CTD had a strong temperature gradient, as shown in Fig. 2e $\left(20.00^{\circ} \mathrm{S}, 52.78^{\circ} \mathrm{E}\right.$ in the Indian Ocean). It was difficult to determine whether the strongly stratified water column was that above the BML, or whether it was caused by the error in CTD measurement or other reasons. For this profile, $d H=4 \mathrm{~m}$ was very small, so all the methods excluded this strong temperature gradient structure and selected the overlying water layer. As a result, $H_{\mathrm{BML}}$ values of 103.3, 97.3, and $93.4 \mathrm{~m}$ were obtained by the threshold, relative variance, and maximum angle methods, respectively, which were close to the visually inspected value of $94.0 \mathrm{~m}$. The value of QI was about 0.8 for all of the methods. The curvature method underestimated $H_{\mathrm{BML}}$ as $66.2 \mathrm{~m}$ with a much lower QI (0.36) because it preferentially selected the depth range with a relatively homogeneous temperature.

When multilayered structures were present near the bottom, as shown in Fig. $2 \mathrm{f}\left(22.14^{\circ} \mathrm{S}, 113.17^{\circ} \mathrm{E}\right.$ in the Indian Ocean), the BML could be readily identified and its $H_{\mathrm{BML}}$ was visually inspected as $17.6 \mathrm{~m}$ with QI $=0.92$. The threshold method obtained the same $H_{\mathrm{BML}}$ value as the visual inspection. The curvature and maximum angle methods slightly underestimated $H_{\mathrm{BML}}$ as 14.9 and $12.9 \mathrm{~m}$, respectively, with corresponding QI values of 0.82 and 0.38 . The relative variance method ignored the bottom layer and captured one of the upper layers, thereby overestimating $H_{\mathrm{BML}}$ as $58.3 \mathrm{~m}$ with a low QI of 0.45 .

\section{b. Comparison with visual inspection}

To reliably evaluate the applicability of these methods for detecting the BML, $H_{\mathrm{BML}}$ was visually inspected in many more temperature profiles. Seventeen WOCE sections, including 1680 stations, were selected in the coverage of the Pacific, Indian, and Atlantic Oceans, as shown in Fig. 1 . We focused on $H_{b}$ rather than $H_{\mathrm{BML}}$ so that the influence of $d H$ could not be considered. Among all the selected sections, the BML could be clearly identified for 1418 stations by visual inspection and using all of the methods.

Figure 3 shows the probability density functions (PDFs) of $H_{b}$ and QI determined by visual inspection and using all of the methods. The visually inspected $H_{b}$ had a lognormal distribution, which is similar to previous observations of the BML thickness (Lozovatsky et al. 2008) and the oceanic surface mixed layer depth (Huang et al. 2018). The median value was $46.8 \mathrm{~m}$ and the $95 \%$ confidence interval was $[4.5,491.8] \mathrm{m}$ when $H_{b}$ was assumed to follow the lognormal distribution. The PDF of QI (Fig. 3b) showed that visual inspection obtained the best estimate of $H_{b}$ and its QI was the most skewed toward 1 with the fewest low values. As shown in Table 2, the median QI of 0.68 was higher than that obtained by any aforementioned method. When we followed the suggestion by Lorbacher et al. (2006) that interpreting the mixed layer is impossible when $\mathrm{QI}<0.50$, visual inspection showed that $81.0 \%$ of the stations had QI larger than 0.5, as shown in Table 2, thereby indicating that the BML could be detected at most stations in the selected WOCE sections.

As shown in Fig. 2a, the threshold method tended to overestimate $H_{b}$, which resulted in a PDF distribution skewed toward thicker values. The median value of 
TABLE 2. Descriptive statistics for $H_{b}$ and QI along the 17 WOCE sections, showing the corresponding median, and $95 \%$ confidence interval or standard deviation values, based on visual inspection and different methods; $P$ is the percentage of those with the determined $H_{b}$ of QI $>0.5$ in all profiles.

\begin{tabular}{|c|c|c|c|c|c|}
\hline \multirow[b]{2}{*}{ Method } & \multicolumn{2}{|r|}{$H_{b}(\mathrm{~m})$} & \multicolumn{3}{|c|}{ QI } \\
\hline & Median & $95 \%$ confidence interval & Median & Std dev & $P(\%)(\mathrm{QI}>0.5)$ \\
\hline Visual inspection & 46.8 & {$[4.5,491.8]$} & 0.68 & 0.20 & 81.0 \\
\hline Threshold & 90.8 & {$[5.9, \quad 1391.1]$} & 0.53 & 0.21 & 53.8 \\
\hline Curvature & 50.4 & {$[2.4,1043.1]$} & 0.57 & 0.28 & 55.4 \\
\hline Maximum angle & 40.9 & {$[1.3,1336.0]$} & 0.54 & 0.30 & 55.1 \\
\hline Relative variance & 59.1 & {$\left[\begin{array}{ll}10.8, & 323.3\end{array}\right]$} & 0.60 & 0.21 & 64.2 \\
\hline Integrated & 58.8 & {$[3.7,646.9]$} & 0.64 & 0.21 & 71.3 \\
\hline
\end{tabular}

$90.8 \mathrm{~m}$ was much larger than that obtained by visual inspection and the upper limit of the $95 \%$ confidence interval was very thick at $1391.1 \mathrm{~m}$. The threshold method obtained the lowest QI median value (0.53) and the smallest station percentage $(53.8 \%)$ with $\mathrm{QI}>0.5$, which was consistent with the more severe deviation in $H_{b}$ compared with the visual inspection (Fig. 3a). The median $H_{b}$ value obtained by the curvature and maximum angle methods were 50.4 and $40.9 \mathrm{~m}$, respectively, which were relatively close to the visually inspected value, as shown in Table 2. However, their PDFs deviated greatly from the lognormal distribution because both methods were prone to yield highly anomalous shallow or thick $H_{b}$, which resulted in wider PDF distributions with wider $95 \%$ confidence intervals ranging from 2.4 to $1043.1 \mathrm{~m}$ for the curvature method and from 1.3 to $1336.0 \mathrm{~m}$ for the maximum angle method. As reported by Lorbacher et al. (2006), the curvature method is not suitable for noisy data and is not highly applicable to the profiles of multistructures, although these types of data and profiles are common in the abyss ocean with weak temperature fluctuations (Armi 1978). Thus, the QI values also varied widely with the curvature and maximum angle methods, which resulted in large standard deviations for QI, as listed in Table 2. These two methods obtained some $H_{b}$ values with high QI values, but they also often yielded $H_{b}$ values with very low QI values, which affected their statistical performance and produced relatively low QI median values ( 0.57 and 0.54 , respectively). The $H_{b}$ values produced by the relative variance method had a lognormal distribution. The median value was slightly larger than the visually inspected one, possibly because this method was affected less by the spiky data and it preferentially selected the most obvious layered structure above the ocean floor, as shown in Fig. 2. The narrow PDF distribution led to the $95 \%$ confidence interval, $[10.8,323.3] \mathrm{m}$, closest to that of the visual inspection. Thus, the relative variance method appeared to determine $H_{b}$ values with much higher QI among all of the methods. The median value of $H_{b}$ was 0.60 , and $64.2 \%$ of the stations had QI $>0.50$, superior to stations using the other methods.

\section{c. An integrated method}

Based on the results of $H_{b}$ and QI shown in Fig. 3, the relative variance method had the highest capacity for determining $H_{b}$ among all the methods. However, as listed in Table 2, the $H_{b}$ values determined by the relative variance method still had rather large deviations compared with the visual inspection results. In some cases, the $H_{b}$ values identified by the other methods were closer to the visually inspected values, as shown in Figs. $2 \mathrm{~d}$ and $2 \mathrm{f}$. Therefore, we updated the relative variance method by considering the results obtained by the other methods. In the integrated method, we assembled a suite of the possible $H_{b}$ values obtained by the four methods and a final $H_{b}$ value was selected to be closest to that of visual inspection by using the data from the 17 WOCE sections. In this approach, the criteria listed below are required in practice.

(i) After comparing the $H_{b}$ values obtained by different methods, we found that the maximum angle method tended to find spurious thicker $H_{b}$ (Table 2). Thus, the $H_{b}$ value determined by the maximum angle method was excluded from the suite of possible $H_{b}$ values when its $H_{b}$ value was larger than $500 \mathrm{~m}$.

(ii) Next, we found that the relative variance method could obtain similar $H_{b}$ values to those of visual inspection when the QI value was larger than 0.7. Using the relative variance method, 389 stations had values of $\mathrm{QI}>0.7$, where the average BML thickness was $0.76 \mathrm{~m}$ larger than that determined by visual inspection. Thus, $H_{b}$ obtained by the relative variance method was selected as the final value when QI was larger than 0.7.

(iii) Otherwise, we used the method where $H_{b}$ had the highest QI. The $H_{b}$ value was selected when QI was either higher than 0.9 or 0.3 higher than that obtained by any other method. 
(iv) Or then, if any two methods found similar upper bounds for BML, their $H_{b}$ values had a higher probability being the actual value. The $H_{b}$ value closer to the ocean bottom was finally selected.

(v) As shown in Fig. 3a, the threshold, curvature, and maximum angle methods were likely to obtain abnormally thick $H_{b}$ values. When the selected $H_{b}$ was determined from any of these methods and it was thicker than $200 \mathrm{~m}$, this was the final choice only if QI was 0.1 higher than that using the relative variance method. Otherwise, the $H_{b}$ value obtained by the relative variance method was selected.

As shown in Fig. 2, the integrated method captured $H_{\mathrm{BML}}$ values that were closer to the visually inspected ones in these profiles. Figure 3 also indicates that the integrated method made clear improvements compared with the four individual methods. In particular, in the range between 10 and $200 \mathrm{~m}$, the $H_{b}$ PDF produced by the integrated method agreed well with that produced by visual inspection. As listed in Table 2, the median $H_{b}$ and QI values with the integrated method were $58.8 \mathrm{~m}$ and 0.64 , respectively, which were closer to the visually inspected values than those produced using the four individual methods.

\section{Comparison with previous studies on $H_{\mathrm{BML}}$}

We also compared our $H_{\mathrm{BML}}$ results obtained by the integrated method with those reported in previous studies. Most of the data used in these studies were unavailable. By using the WOCE database, we tried to find three stations at most located nearest to those used for earlier observations within $100 \mathrm{~km}$, or only one station when the nearest station was more than $100 \mathrm{~km}$ apart from those in the earlier observations. These profiles and the determined $H_{\mathrm{BML}}$ are shown in Fig. 4, and they are compared with previous reported results in Table 3.

Most previous deep-ocean surveys were performed in the Atlantic Ocean. In the North Atlantic, such as in the Hatteras Abyssal Plain (Armi and Millard 1976), the Sohm Abyssal Plain (Armi 1978), the Eastward Scarp of the Bermuda Rise (Bird et al. 1982), the Porcupine Abyssal Plain (Turnewitsch and Springer 2001), and other areas (Grant et al. 1985; Klein and Mittelstaedt 1992), the $H_{\mathrm{BML}}$ values for the nearest WOCE stations varied between 30 and $180 \mathrm{~m}$ with large QI values in most cases (Fig. 4a), as shown in Table 3, which were similar to the previous observations. In the Madeira Abyssal Plain, it was reported that the BML could not be readily recognized from November 1980 to July 1981 (Saunders 1983). We found that the nearest stations had the well-shaped BMLs with $H_{\mathrm{BML}}$ values of $50-90 \mathrm{~m}$ (Fig. 4b), which were measured almost at the same locations in the summer 20 or 30 years later. In the Blake Ridge, $H_{\mathrm{BML}}$ appeared to be thicker than $100 \mathrm{~m}$ (Eittreim et al. 1975; Stahr and Sanford 1999). We found that the nearest ocean station had an $H_{\mathrm{BML}}$ value of $182 \mathrm{~m}$ (Fig. 4c). In the Brazil Basin, Vema Sill, and Vema Channel, it was reported that $H_{\mathrm{BML}}$ varied from 50 to $500 \mathrm{~m}$ (Hogg et al. 1982; Durrieu de Madron and Weatherly 1994; Zenk and Hogg 1996; Zenk 2008). The $H_{\mathrm{BML}}$ values of the nearest ocean stations were generally thinner $(\sim 50 \mathrm{~m})$ except for some stations with thick $H_{\text {BML }}$ up to $293.6 \mathrm{~m}$. The different results compared with those in previous studies may be attributed to the different definitions of $H_{\mathrm{BML}}$. For example, according to Durrieu de Madron and Weatherly (1994), a density anomaly, varying around $0.01 \mathrm{~kg} \mathrm{~m}^{-3}$, was used to define $H_{\mathrm{BML}}$, even though the density was inhomogeneous within the defined depth range (e.g., Fig. 14 in Durrieu de Madron and Weatherly 1994). As shown in Figs. $4 d$ and 4e, we determined the $H_{\mathrm{BML}}$ values robustly for most of the nearest stations, which is confirmed by their high QI values.

Fewer previous deep-ocean surveys were performed in oceans other than the Atlantic. Off central California, the average value of $H_{\mathrm{BML}}$ was reported to be $40 \mathrm{~m}$ with a range of 15-80 $\mathrm{m}$ (Beaulieu and Baldwin 1998). The nearest WOCE stations (within $100 \mathrm{~km}$ ) had $H_{\mathrm{BML}}$ values in the range of $20-60 \mathrm{~m}$ (Fig. 4f). In the eastern tropical Pacific, Hayes $(1979,1980)$ found that it was difficult to detect the presence of a mixed layer. As shown in Fig. 4g, almost half of the eight nearest stations had a well-shaped BML, and the integrated method determined a relatively thick BML in this region, which was confirmed by the fairly high QI values. In the Pacific margin of the Antarctic Peninsula, the Ekman layer thickness $(170 \mathrm{~m})$ was deduced based on the flow currents (Giorgetti et al. 2003). The closest WOCE stations had an obvious homogeneous BML, where $H_{\mathrm{BML}}$ varied from 33 to $171 \mathrm{~m}$ (Fig. 4h). In the western and southern regions of Indian Ocean, $H_{\mathrm{BML}}$ was inferred to be on the order of $50-100 \mathrm{~m}$ based on the bottom ${ }^{222} \mathrm{Rn}$ and potential temperature profiles (Chung and Kim 1980). The $H_{\mathrm{BML}}$ values for the closest WOCE stations ranged from 17 to $107 \mathrm{~m}$, as shown in Fig. 4i. Most of the $H_{\mathrm{BML}}$ values had quite high QI values, as listed in Table 3. Compared with previous observations, our proposed integrated method is highly efficient at identifying the values of $H_{\mathrm{BML}}$ in different oceans.

\section{Summary and discussion}

In this study, using full-depth CTD profiles from the WOCE program, we first examined the applicability of 

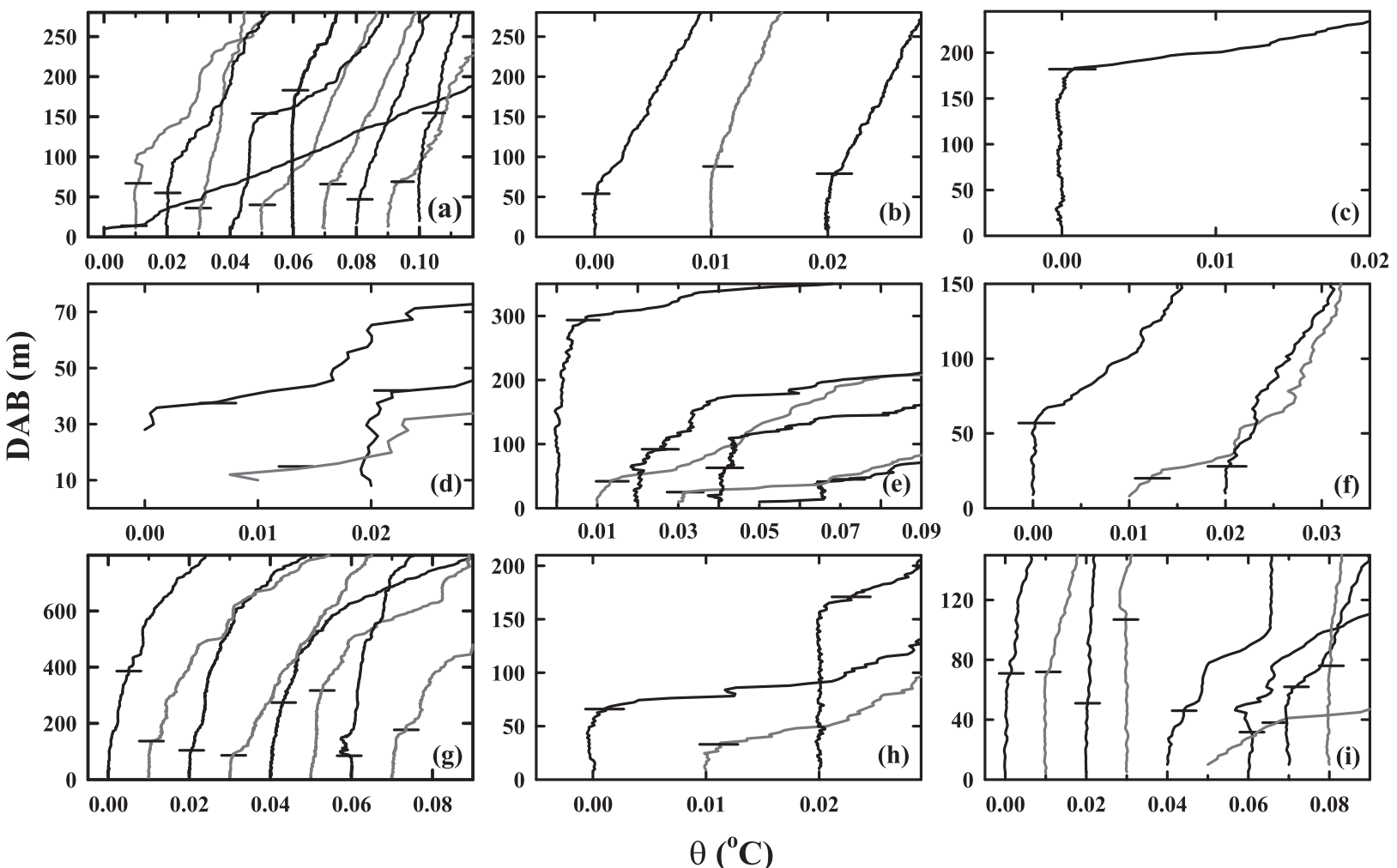

FIG. 4. Potential temperature profiles and the corresponding upper bound of BML at the nearest WOCE stations in comparison with previous observations in the (a) northeast Atlantic Ocean, (b) Madeira Abyssal Plain, (c) Hatteras Abyssal Plain and Blake Outer Ridge, (d) Brazil Basin, (e) Vema Sill and the Vema Channel, (f) off central California, (g) eastern tropical Pacific Ocean, (h) Antarctic Peninsula Pacific margin, and (i) Indian Ocean. The temperature profiles are plotted in the same order as those in Table 3 . They are accordingly shifted by $0.01^{\circ} \mathrm{C}$ based on their bottom temperature in order to avoid overlapping, and they are plotted alternately as black and gray curves for clarity.

the threshold method for identifying $H_{\mathrm{BML}}$ as well as some other methods used for the surface ocean mixed layer depth, that is, the curvature (Lorbacher et al. 2006), maximum angle (Chu and Fan 2011), and relative variance (Huang et al. 2018) methods. For the temperature profiles examples, we found that any of these methods can be used to identify $H_{\mathrm{BML}}$, but the obtained $H_{\mathrm{BML}}$ values were not always accurate compared with visual inspections. Based on comparisons with visual inspections of the temperature profiles along 17 WOCE sections covering the Atlantic, Indian, and Pacific Oceans, we evaluated the efficiency of each method, qualified by the median and $95 \%$ confidence interval of $H_{b}$ and by the quality index QI. We found that the relative variance method performed best because the $95 \%$ confidence interval for $H_{b}$ was closest to that based on the visual inspection and the median QI value $(0.60)$ was highest among all of the methods. However, the quality of the $H_{b}$ values determined by this method was still far below that based on the visual inspection, where the visual inspection found $81 \%$ of stations with $\mathrm{QI}>0.5$, whereas the relative variance method found at most $64 \%$ of stations with $\mathrm{QI}>0.5$.

Based on the results obtained using the different methods, we developed an integrated method by assembling a suite of the possible $H_{\mathrm{BML}}$ values with these four methods. According to certain criteria, the final $H_{\mathrm{BML}}$ value was selected as that closest to the visually inspected value. It is confirmed by evidence that the median QI value (0.64) with the integrated method was closest to that produced by visual inspection, and many more stations $(71 \%)$ had $\mathrm{QI}>0.5$. We also compared the $H_{\mathrm{BML}}$ values determined using the integrated method with those reported in previous studies. Most of the data from these studies were unavailable, so we tried to find the WOCE stations nearest to the previous observations. In most ocean regions, such as in the northeast Atlantic Ocean, Blake Ridge, off central California, and Indian Ocean, our $H_{\mathrm{BML}}$ values were consistent with earlier observations within the variance range. In the Madeira Abyssal Plain and the eastern tropical Pacific Ocean, the BML was reported as undetectable in earlier 


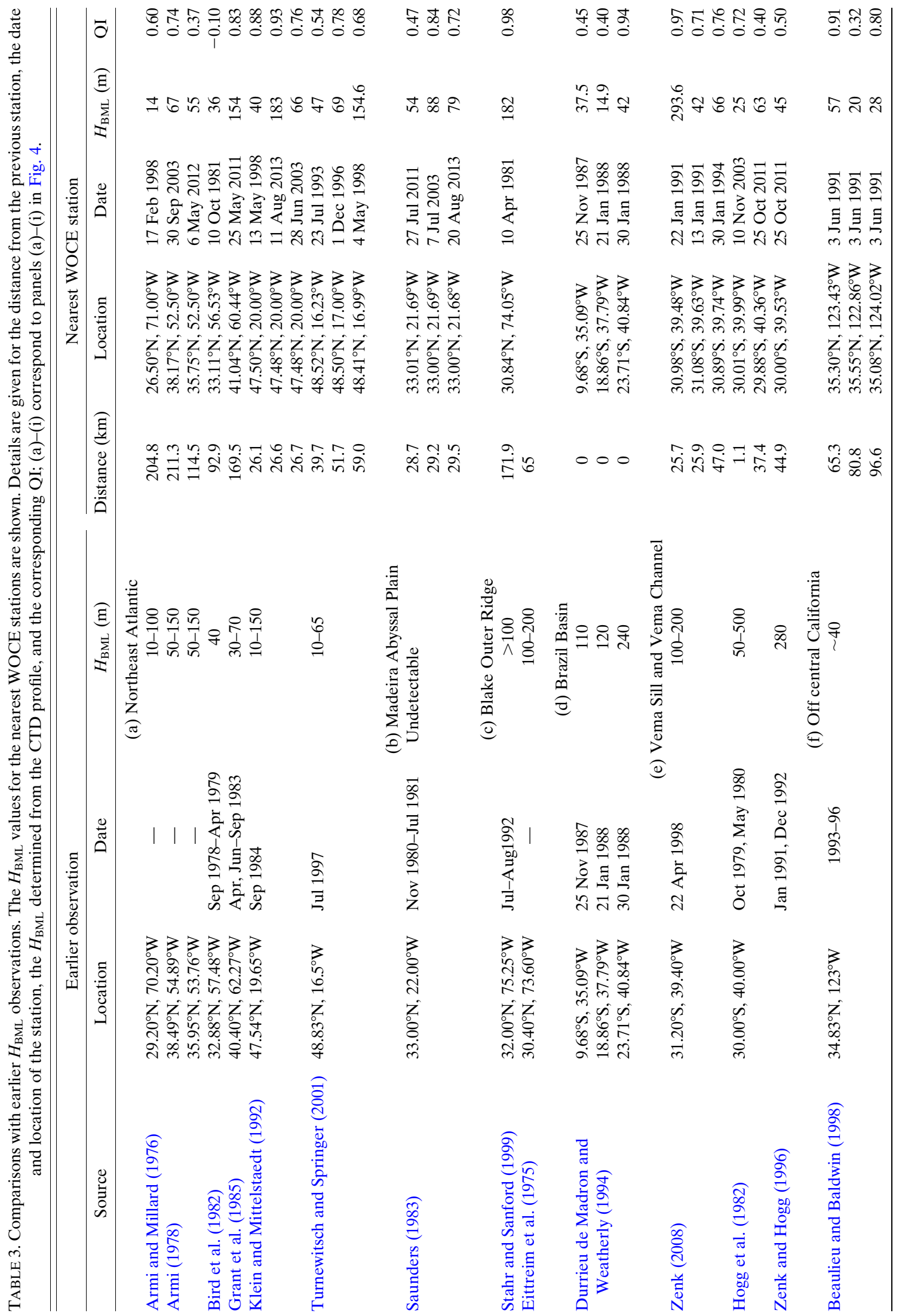




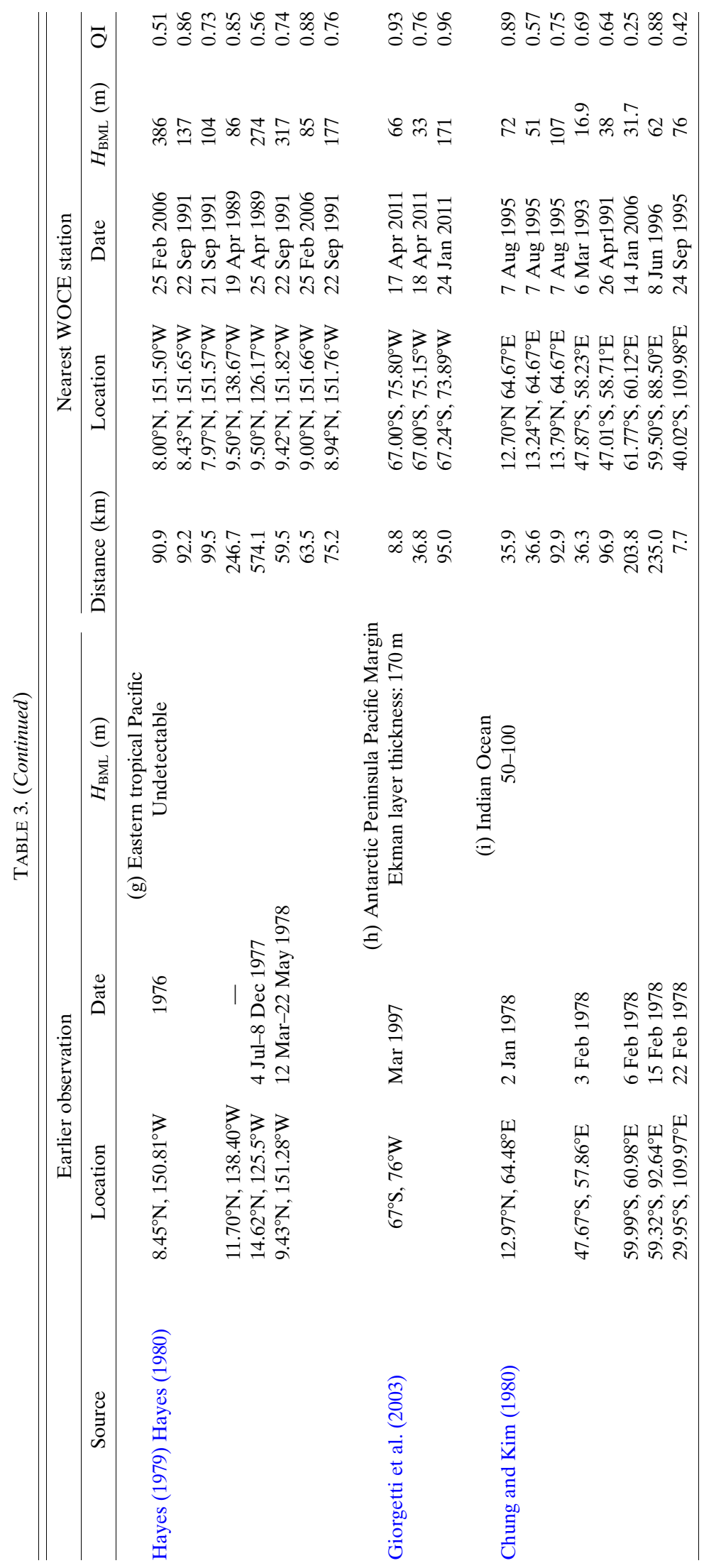


works, but we found that some of the nearest WOCE stations had the well-shaped BMLs and their $H_{\mathrm{BML}}$ values could be determined accurately with the integrated method. In the Brazil Basin, the $H_{\mathrm{BML}}$ values determined from the WOCE stations were thinner than those reported previously, where density anomalies were used to define $H_{\mathrm{BML}}$, even though the density was inhomogeneous within the defined depth range in some cases. According to the comparisons with the visual inspections and previous studies, the integrated method could be used to determine $H_{\mathrm{BML}}$ in different oceans, which might be useful for quantifying the spatial and temporal variances in BML globally.

Acknowledgments. This study was supported by the NSF of China (91752108, 41476167, 41776033, and 41706029) and the NSF of Guangdong Province, China (2016A030311042); the Guangzhou Science and Technology Program key project (201804020056); and the Strategic Priority Research Program of the Chinese Academy of Sciences (XDA11030302). We thank everyone who helped to collect, calibrate, process, and archive the WOCE, CLIVAR, and GO-SHIP hydrographic section data.

\section{REFERENCES}

Adcroft, A., J. R. Scott, and J. Marotzke, 2001: Impact of geothermal heating on the global ocean circulation. Geophys. Res. Lett., 28, 1735-1738, https://doi.org/10.1029/2000GL012182.

Amos, A. F., A. L. Gordon, and E. D. Schneider, 1971: Water masses and circulation patterns in the region of the BlakeBahama outer ridge. Deep-Sea Res. Oceanogr. Abstr., 18, 145-165, https://doi.org/10.1016/0011-7471(71)90106-9.

Armi, L., 1978: Some evidence for boundary mixing in the deep ocean. J. Geophys. Res., 83, 1971-1979, https://doi.org/10.1029/ JC083iC04p01971.

_ , and R. C. Millard, 1976: The bottom boundary layer of the deep ocean. J. Geophys. Res., 81, 4983-4990, https://doi.org/ 10.1029/JC081i027p04983.

Banyte, D., D. A. Smeed, and M. M. Maqueda, 2018: The weakly stratified bottom boundary layer of the global ocean. J. Geophys. Res. Oceans, 123, 5587-5598, https://doi.org/ 10.1029/2018JC013754.

Beaulieu, S., and R. Baldwin, 1998: Temporal variability in currents and the benthic boundary layer at an abyssal station off central California. Deep-Sea Res. II, 45, 587-615, https:// doi.org/10.1016/S0967-0645(97)00095-7.

Bird, A. A., G. L. Weatherly, and M. Wimbush, 1982: A study of the bottom boundary layer over the Eastward Scarp of the Bermuda Rise. J. Geophys. Res., 87, 7941-7954, https:// doi.org/10.1029/JC087iC10p07941.

Bowden, K., 1978: Physical problems of the benthic boundary layer. Geophys. Surv., 3, 255-296, https://doi.org/10.1007/ BF01449556.

Brainerd, K., and M. Gregg, 1995: Surface mixed and mixing layer depths. Deep-Sea Res. I, 42, 1521-1543, https://doi.org/10.1016/ 0967-0637(95)00068-H.
Caldwell, D. R., 1976: Fine-scale temperature structure in the bottom mixed layer on the Oregon shelf. Deep-Sea Res. Oceanogr. Abstr., 23, 1025-1035, https://doi.org/10.1016/00117471(76)90878-0.

Chu, P. C., and C. Fan, 2010: Optimal linear fitting for objective determination of ocean mixed layer depth from glider profiles. J. Atmos. Oceanic Technol., 27, 1893-1898, https://doi.org/ 10.1175/2010JTECHO804.1.

— mixed layer depth from seaglider data. J. Oceanogr., 67, 219230, https://doi.org/10.1007/s10872-011-0019-2.

Chung, Y., and K. Kim, 1980: Excess ${ }^{222} \mathrm{Rn}$ and the benthic boundary layer in the western and southern Indian Ocean. Earth Planet. Sci. Lett., 49, 351-359, https://doi.org/10.1016/ 0012-821X(80)90078-3.

de Boyer Montégut, C., G. Madec, A. S. Fischer, A. Lazar, and D. Iudicone, 2004: Mixed layer depth over the global ocean: An examination of profile data and a profile-based climatology. J. Geophys. Res., 109, C12003, https://doi.org/10.1029/ 2004JC002378.

Defant, A., 1936: Die troposphare des atlantischen ozeans. Schichtung und Zierkulation des Atlantischen Ozeans, Wissenschaftliche Ergebnisse der Deutschen Atlantischen Expedition auf dem Forschungs- und Vermessungsschiff "Meteor" 1925-1927, Vol. 6, Part 1, De Gruyter, 290-411.

Durrieu de Madron, X., and G. Weatherly, 1994: Circulation, transport and bottom boundary layers of the deep currents in the Brazil Basin. J. Mar. Res., 52, 583-638, https://doi.org/ 10.1357/0022240943076975.

— , and Coauthors, 2017: Deep sediment resuspension and thick nepheloid layer generation by open-ocean convection. J. Geophys. Res. Oceans, 122, 2291-2318, https://doi.org/ 10.1002/2016JC012062.

Eittreim, S., P. E. Biscaye, and A. F. Amos, 1975: Benthic nepheloid layers and the Ekman thermal pump. J. Geophys. Res., 80, 5061-5067, https://doi.org/10.1029/JC080i036p05061.

Ferrari, R., A. Mashayek, T. J. McDougall, M. Nikurashin, and J.-M. Campin, 2016: Turning ocean mixing upside down. J. Phys. Oceanogr., 46, 2239-2261, https://doi.org/10.1175/ JPO-D-15-0244.1.

Galbraith, P. S., and D. E. Kelley, 1996: Identifying overturns in CTD profiles. J. Atmos. Oceanic Technol., 13, 688-702, https:// doi.org/10.1175/1520-0426(1996)013<0688:IOICP>2.0.CO;2.

Giorgetti, A., A. Crise, R. Laterza, L. Perini, M. Rebesco, and A. Camerlenghi, 2003: Water masses and bottom boundary layer dynamics above a sediment drift of the Antarctic Peninsula Pacific margin. Antarct. Sci., 15, 537-546, https:// doi.org/10.1017/S0954102003001652.

Gloor, M., A. Wüest, and M. Münnich, 1994: Benthic boundary mixing and resuspension induced by internal seiches. Hydrobiologia, 284, 59-68, https://doi.org/10.1007/BF00005731.

Grant, W. D., and O. S. Madsen, 1986: The continental-shelf bottom boundary layer. Annu. Rev. Fluid Mech., 18, 265-305, https://doi.org/10.1146/annurev.fl.18.010186.001405.

— A. J. Williams, and T. F. Gross, 1985: A description of the bottom boundary layer at the HEBBLE site: Low-frequency forcing, bottom stress and temperature structure. Mar. Geol., 66, 219-241, https://doi.org/10.1016/0025-3227(85)90031-3.

Hayes, S. P., 1979: Benthic current observations at DOMES sites A, B, and C in the tropical North Pacific Ocean. Marine Geology and Oceanography of the Pacific Manganese Nodule Province, J. L. Bischoff and D. Z. Pipper, Eds., Springer, 83-112. 
- 1980: The bottom boundary layer in the eastern tropical Pacific. J. Phys. Oceanogr., 10, 315-329, https://doi.org/ 10.1175/1520-0485(1980)010<0315:TBBLIT>2.0.CO;2.

Hogg, N., P. E. Biscaye, W. D. Gardner, and W. J. Schmitz Jr., 1982: On the transport and modification of Antarctic bottom water in the Vema Channel. J. Mar. Res., 40, 1-263.

Holte, J., and L. Talley, 2009: A new algorithm for finding mixed layer depths with applications to Argo data and Subantarctic Mode Water formation. J. Atmos. Oceanic Technol., 26, 1920-1939, https://doi.org/10.1175/2009JTECHO543.1.

Huang, P., X. Lu, and S. Zhou, 2018: An objective method for determining ocean mixed layer depth with applications to WOCE data. J. Atmos. Oceanic Technol., 35, 441-458, https:// doi.org/10.1175/JTECH-D-17-0104.1.

Kara, A. B., P. A. Rochford, and H. E. Hurlburt, 2000: An optimal definition for ocean mixed layer depth. J. Geophys. Res., $\mathbf{1 0 5}$, 16 803-16 821, https://doi.org/10.1029/2000JC900072.

Klein, H., and E. Mittelstaedt, 1992: Currents and dispersion in the abyssal northeast Atlantic. Results from the NOAMP field program. Deep-Sea Res., 39A, 1727-1745, https://doi.org/ 10.1016/0198-0149(92)90026-P.

Lavender, K. L., R. E. Davis, and W. B. Owens, 2002: Observations of open-ocean deep convection in the Labrador Sea from subsurface floats. J. Phys. Oceanogr., 32, 511-526, https://doi.org/ 10.1175/1520-0485(2002)032<0511:OOOODC >2.0.CO;2.

Lentz, S. J., and J. H. Trowbridge, 1991: The bottom boundary layer over the northern California shelf. J. Phys. Oceanogr. 21, 1186-1201, https://doi.org/10.1175/1520-0485(1991)021<1186: TBBLOT $>2.0 . \mathrm{CO} ; 2$.

Levitus, S., 1982: Climatological Atlas of the World Ocean. NOAA Prof. Paper 13, 173 pp. and 17 microfiche.

Lorbacher, K., D. Dommenget, P. Niiler, and A. Köhl, 2006: Ocean mixed layer depth: A subsurface proxy of ocean-atmosphere variability. J. Geophys. Res., 111, C07010, https://doi.org/ 10.1029/2003JC002157.

Lozovatsky, I., and S. Shapovalov, 2012: Thickness of the mixed bottom layer in the northern Atlantic. Oceanology, 52, 447452, https://doi.org/10.1134/S0001437012010134.

_, H. Fernando, and S. Shapovalov, 2008: Deep-ocean mixing on the basin scale: Inference from North Atlantic transects. Deep-Sea Res. I, 55, 1075-1089, https://doi.org/10.1016/ j.dsr.2008.05.003.

Lukas, R., and E. Lindstrom, 1991: The mixed layer of the western equatorial Pacific Ocean. J. Geophys. Res., 96, 3343-3357, https://doi.org/10.1029/90JC01951.

McDougall, T. J., and R. Ferrari, 2017: Abyssal upwelling and downwelling driven by near-boundary mixing. J. Phys. Oceanogr., 47, 261-283, https://doi.org/10.1175/JPO-D-16-0082.1.

Obata, A., J. Ishizaka, and M. Endoh, 1996: Global verification of critical depth theory for phytoplankton bloom with climatological in situ temperature and satellite ocean color data. J. Geophys. Res., 101, 657-667, https://doi.org/10.1029/ 96JC01734.

Perlin, A., J. N. Moum, J. M. Klymak, M. D. Levine, T. Boyd, and P. M. Kosro, 2005: A modified law-of-the-wall applied to oceanic bottom boundary layers. J. Geophys. Res., 110, C10S10, https://doi.org/10.1029/2004JC002310.

$-,-,-\ldots, \ldots$, and,- 2007: Organization of stratification, turbulence, and veering in bottom Ekman layers. J. Geophys. Res., 112, C05S90, https://doi.org/10.1029/ 2004JC002641.
Pollard, R. T., P. B. Rhines, and R. O. Thompson, 1972: The deepening of the wind-mixed layer. Geophys. Fluid Dyn., 4, 381-404, https://doi.org/10.1080/03091927208236105.

Richards, K., 1982: Modeling the benthic boundary layer. J. Phys. Oceanogr., 12, 428-439, https://doi.org/10.1175/1520-0485(1982) $012<0428$ :MTBBL $>2.0 . \mathrm{CO} ; 2$.

- 1990: Physical processes in the benthic boundary layer. Philos. Trans. Roy. Soc. London, 331A, 3-13, https://doi.org/ 10.1098/rsta.1990.0052.

Saunders, P. M., 1983: Benthic observations on the Madeira Abyssal Plain: Currents and dispersion. J. Phys. Oceanogr., 13, 1416-1429, https://doi.org/10.1175/1520-0485(1983)013<1416: BOOTMA $>2.0 . \mathrm{CO} ; 2$.

Schaeffer, A., M. Roughan, and J. Wood, 2014: Observed bottom boundary layer transport and uplift on the continental shelf adjacent to a western boundary current. J. Geophys. Res. Oceans, 119, 4922-4939, https://doi.org/10.1002/2013JC009735.

Stahr, F. R., and T. B. Sanford, 1999: Transport and bottom boundary layer observations of the North Atlantic Deep Western Boundary Current at the Blake Outer Ridge. Deep-Sea Res. II, 46, 205-243, https://doi.org/10.1016/S0967-0645(98)00101-5.

Thomson, R. E., and I. V. Fine, 2003: Estimating mixed layer depth from oceanic profile data. J. Atmos. Oceanic Technol., 20, 319-329, https://doi.org/10.1175/1520-0426(2003)020<0319: EMLDFO $>2.0 . \mathrm{CO} ; 2$.

Turnewitsch, R., and B. M. Springer, 2001: Do bottom mixed layers influence ${ }^{234} \mathrm{Th}$ dynamics in the abyssal near-bottom water column? Deep-Sea Res. I, 48, 1279-1307, https://doi.org/10.1016/ S0967-0637(00)00104-7.

Valipour, R., D. Bouffard, and L. Boegman, 2015: Parameterization of bottom mixed layer and logarithmic layer heights in central Lake Erie. J. Great Lakes Res., 41, 707-718, https:// doi.org/10.1016/j.jglr.2015.06.010.

Weatherly, G. L., 1972: A study of the bottom boundary layer of the Florida Current. J. Phys. Oceanogr., 2, 54-72.

, and P. J. Martin, 1978: On the structure and dynamics of the oceanic bottom boundary layer. J. Phys. Oceanogr., 8, 557-570, https://doi.org/10.1175/1520-0485(1978)008<0557: OTSADO $>2.0 . \mathrm{CO} ; 2$

Wüest, A., and A. Lorke, 2003: Small-scale hydrodynamics in lakes. Annu. Rev. Fluid Mech., 35, 373-412, https://doi.org/ 10.1146/annurev.fluid.35.101101.161220.

Wunsch, C., 1970: On oceanic boundary mixing. Deep-Sea Res. Oceanogr. Abstr., 17, 293-301, https://doi.org/10.1016/00117471(70)90022-7.

Wyrtki, K., 1964: The thermal structure of the eastern Pacific Ocean. Deutsche Hydrographische Zeitschrift, Ergänzungsheft Reihe, Ser. A, No. 8, 84 pp.

Zenk, W., 2008: Temperature fluctuations and current shear in Antarctic Bottom Water at the Vema Sill. Prog. Oceanogr., 77, 276-284, https://doi.org/10.1016/j.pocean.2006.05.006. , and N. Hogg, 1996: Warming trend in Antarctic Bottom Water flowing into the Brazil Basin. Deep-Sea Res. I, 43, 14611473, https://doi.org/10.1016/S0967-0637(96)00068-4.

Zhou, S.-Q., and Y.-Z. Lu, 2013: Characterization of double diffusive convection steps and heat budget in the deep Arctic Ocean. J. Geophys. Res. Oceans, 118, 6672-6686, https:// doi.org/10.1002/2013JC009141.

Zilitinkevich, S., and I. Esau, 2002: On integral measures of the neutral barotropic planetary boundary layer. Bound.-Layer Meteor., 104, 371-379, https://doi.org/10.1023/A:1016540808958. 